\title{
ZE10 MAGNESIUM ALLOY CORROSION PROPERTIES IMPROVEMENT BY UNCONVENTIONAL FLUORIDE CONVERSION COATING
}

\author{
1Jaromír WASSERBAUER, 1, 2Juliána DRÁBIKOVÁ, ${ }^{1,3}$ Stanislava FINTOVÁ, ${ }^{1,4}$ Pavel DOLEŽAL, \\ ${ }^{2}$ Branislav HADZIMA \\ ${ }^{1}$ Materials Research Centre, Faculty of Chemistry, Brno University of Technology, Czech Republic, EU, \\ wasserbauer@fch.vut.cz \\ ${ }^{2}$ Research Centre of the University of Žilina, University of Žilina, Slovak Republic, EU \\ 3Institute of Physics of Materials, Academy of Sciences of the Czech Republic, Brno, Czech Republic, EU \\ ${ }^{4}$ Institute of Materials Science and Engineering, Faculty of Mechanical Engineering, Brno University of \\ Technology, Brno, Czech Republic, EU
}

https://doi.org/10.37904/metal.2019.729

\begin{abstract}
The paper offers an analysis of the fluoride conversion coating prepared on ZE10 magnesium alloy with the aim to improve material corrosion properties with respect to the biocompatibility of the alloy. The coating was prepared via unconventional process, by immersion of the alloy in $\mathrm{Na}\left[\mathrm{BF}_{4}\right]$ molten salt at 430 and $450{ }^{\circ} \mathrm{C}$ for various treatment times. The coating was analysed in terms of scanning electron microscopy, energy dispersive X-ray spectroscopy and electrochemical impedance spectroscopy. The coating was shown to be compact and homogenous with intermetallic particles incorporated in the coating. Significantly higher values of the polarization resistance were estimated for the coated specimens when compared to the untreated ZE10 alloy in simulated body fluid solution at $37 \pm 2{ }^{\circ} \mathrm{C}$.
\end{abstract}

Keywords: Wrought ZE10 magnesium alloy, fluoride conversion coating, corrosion, electrochemical impedance spectroscopy

\section{INTRODUCTION}

Magnesium and its alloys have been investigated in recent years as biodegradable implant materials due to their good biomedical properties and as they do not require secondary surgical procedure for removal of the implant due to the biodegradability [1]. However, the high corrosion rate of magnesium is a limiting factor for magnesium based materials application in chloride containing environments [2]. The high corrosion rate results in high $\mathrm{H}_{2}$ bubbles evolution having a harmful influence on human tissues due to the saturation [3]. There exist two basic ways how to improve the corrosion resistance of $\mathrm{Mg}$ and its alloys: (i) tailor alloy chemical composition and microstructure and (ii) surface treatment.

The fluoride conversion coatings were shown to be an appropriate barrier increasing magnesium corrosion resistance and providing biocompatibility [3,4]. Two methods are used in the literature for the coatings preparation. The conventional method is based on dipping of magnesium based alloys to the HF solutions [57], and the unconventional method lies in dipping the material to the $\mathrm{Na}\left[\mathrm{BF}_{4}\right]$ salt melt. The fluoride conversion coating prepared by dipping of $A Z 61$ magnesium alloy into $\mathrm{Na}\left[\mathrm{BF}_{4}\right]$ salt melt was investigated in our recent studies $[8,9]$. Unconventional fluoride conversion coating was consisted of two layers. The primary layer was composed of $\mathrm{MgF}_{2}$ and it provided a corrosion protective barrier for the alloy. The secondary layer was composed of $\left.\mathrm{Na}_{2} \mathrm{MgF}_{3}\right][8,9]$. The presence of $\mathrm{Na}$ could be associated with presence of toxic NaF compound in secondary layer, so the layer was removed by boiling in distilled water $[8,9]$.

Unconventional fluoride conversion coating was prepared by immersion of the alloy in $\mathrm{Na}_{[}\left[\mathrm{BF}_{4}\right]$ molten salt at 430 and $450^{\circ} \mathrm{C}$ for various treatment times with the aim to improve electrochemical corrosion properties of 
ZE10 magnesium alloy. The coating was analysed in terms of scanning electron microscopy, chemical composition and electrochemical impedance spectroscopy.

\section{EXPERIMENTAL MATERIAL AND METHODOLOGY}

\subsection{Experimental material}

The ZE10 wrought magnesium alloy delivered in the form of a sheet was used as the experimental material for the fluoride conversation coating preparation. In Figure 1 is shown the microstructure of the material in a direction parallel to the sheet production. Average grain size was determined as $11 \pm 2 \mu \mathrm{m}$. In the microstructure were observed intermetallic phase particles of $M g_{7} Z n_{3}(R E)$. The microstructure can be considered as a homogenous from the macroscopic point of view.
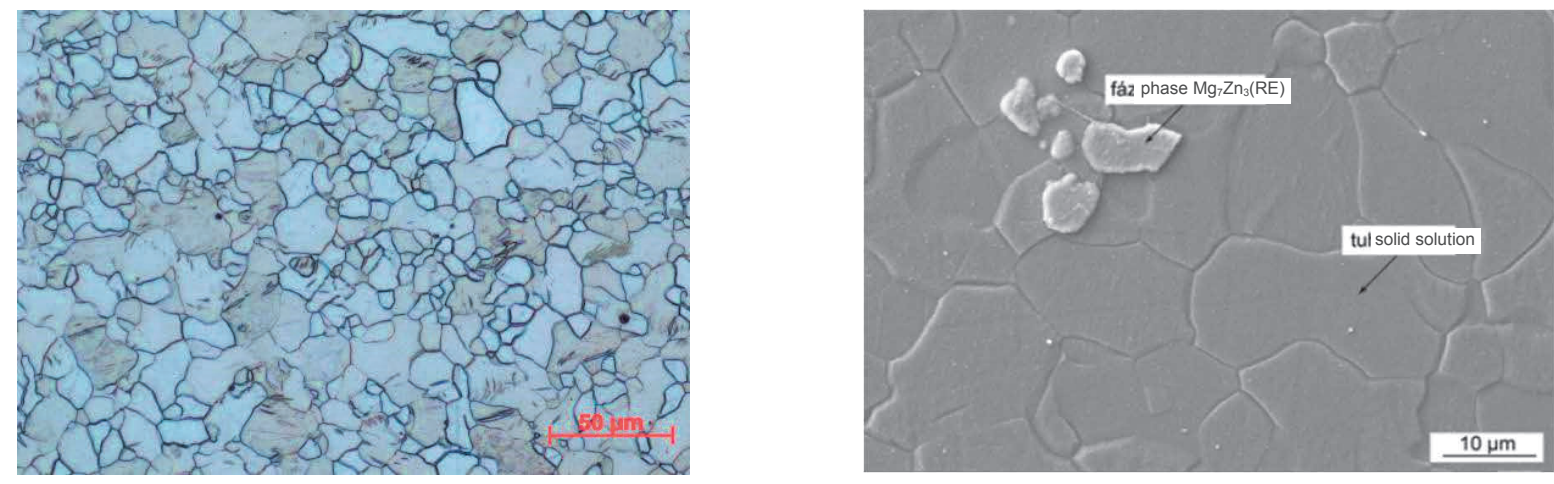

Figure 1 As-received microstructure of ZE10 a) polyhedral grains, b) intermetallic phase particles

\subsection{Coating preparation and characterization}

The coating was prepared on polished specimens with the dimensions of $38 \times 40 \mathrm{~mm}$ and a thickness of 2 $\mathrm{mm}$ by chemical reaction of the ZE10 magnesium alloy and $\mathrm{Na}\left[\mathrm{BF}_{4}\right]$ salt melt at 430 and $450{ }^{\circ} \mathrm{C}$. An amount of $130 \mathrm{~g}$ of $\mathrm{Na}\left[\mathrm{BF}_{4}\right]$ salt was poured into the corundum crucible melted and temperate in an electric furnace. The specimens were dipped into the molten salt for various treatment times; 0.5, 1, 2, 4, 8 and $12 \mathrm{~h}$. After the treatment time, the specimens were removed from the crucible and subsequently dipped in a boiling distilled water for 0.5 to $3 \mathrm{~h}$. Specimens were boiled in distilled water to remove the salt residuals and the soluble $\mathrm{Na}\left[\mathrm{MgF}_{3}\right]$ secondary coating layer $[8,9]$.

The morphology and integrity of the coating were analyzed using scanning electron microscopy (SEM model Zeis EVO LS10). Energy dispersive X-ray spectroscopy (EDS, model OXFORD INSTRUMENTS X-MAX $80 \mathrm{~mm}^{2}$ ) was used to determine the coating chemical composition. Surface and cross-section mapping was performed to estimate the quality of specimens coverage and elements distribution within the coating. The thickness of the primary layer was measured on 10 places of the cross-section of the specimen.

\subsection{Electrochemical corrosion tests}

Electrochemical corrosion characteristic of untreated and coated ZE10 magnesium alloy were analyzed by electrochemical impedance spectroscopy (EIS) in the environment of simulated body fluid (SBF), [9], at $37 \pm$ $2{ }^{\circ} \mathrm{C}$. EIS measurement was carried out using the BioLogic VSP-300 potentiostat with a three-electrode cell model. The platinum electrode was a counter electrode, the saturated calomel electrode was a reference electrode (SCE, $+0.242 \mathrm{~V}$ vs. SHE) and the specimen was used as a working electrode. The area of $1 \mathrm{~cm}^{2}$ of the specimen was exposed to the SBF solution during the electrochemical testing. The EIS scan frequency was ranged from $100 \mathrm{kHz}$ to $10 \mathrm{mHz}$ and the perturbation amplitude was $5 \mathrm{mV}$. Experiments were performed thrice for reproducibility. 


\section{RESULTS}

\subsection{Coating characterization}

The surface morphology of the primary layer of the fluoride conversion coating prepared on ZE10 in the $\mathrm{Na}\left[\mathrm{BF}_{4}\right]$ salt melt at 430 and $450{ }^{\circ} \mathrm{C}$ for 0.5 , and $12 \mathrm{~h}$ is shown in Figures 2a-d. EDS map analysis revealed heterogeneous areas related with the presence of $M_{7} Z_{7} n_{3}(R E)$ intermetallic phase particles. The surface defects in the form of cavities and cracks were observed in areas close to particles of intermetallic phase. EDS analysis of the surface defects did not reveal the coated material, only the coating was detected.

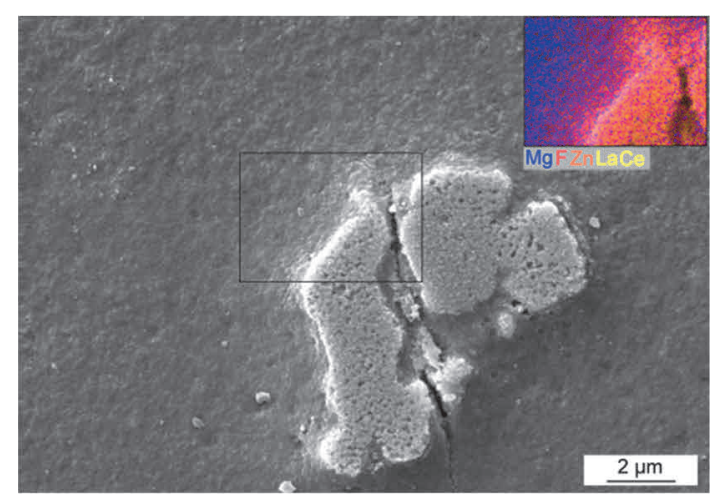

a) $0.5 \mathrm{~h}, 430^{\circ} \mathrm{C}$

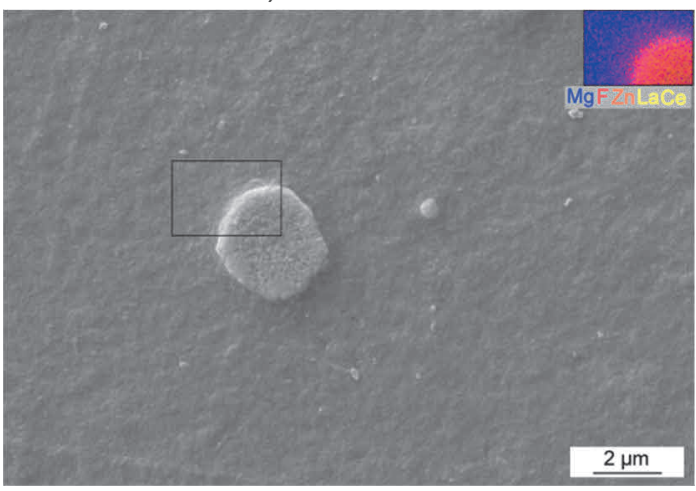

c) $0.5 \mathrm{~h}, 450^{\circ} \mathrm{C}$

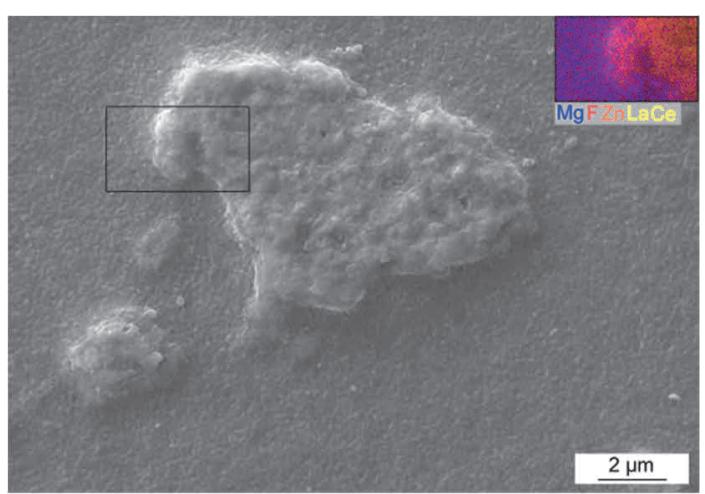

b) $12 \mathrm{~h}, 430^{\circ} \mathrm{C}$

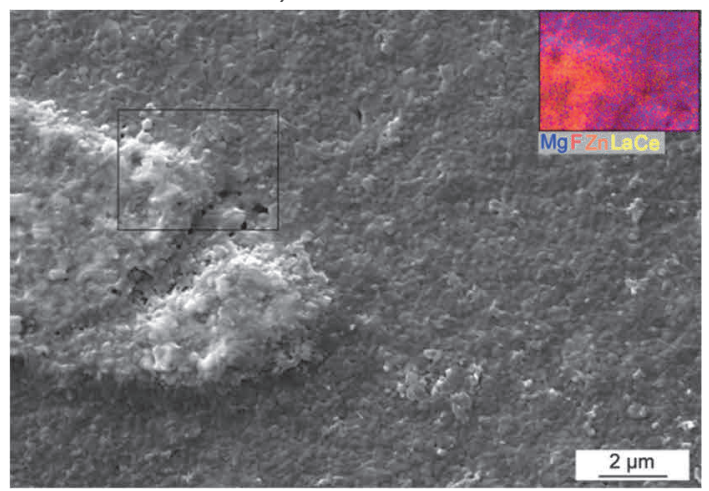

d) $12 \mathrm{~h}, 450{ }^{\circ} \mathrm{C}$

Figure 2 Surface morphology of the fluoride conversion coating, SEM + EDS

SEM and EDS analysis of the coated specimens cross-section were used to analyse the coating thickness and homogeneity. The created coating was compact and with a uniform thickness in whole the inspected surface area except places of intermetallic phase particles presence, Figure 3 . The primary layer was on the $\mathrm{Mg}-\mathrm{F}$ basis and detected intermetallic phase particles contained $\mathrm{F}$ in their volume.

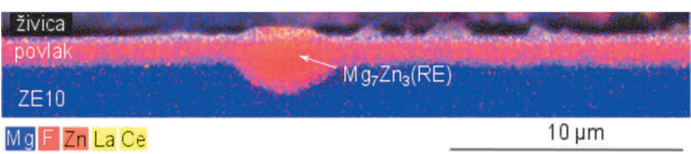

a) $430{ }^{\circ} \mathrm{C}$

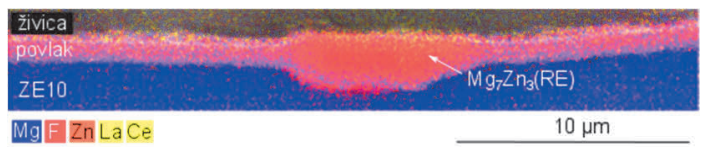

b) $450{ }^{\circ} \mathrm{C}$

Figure 3 Cross-section of fluoride conversion coatings, SEM + EDS

The measured thickness of the coatings prepared at different conditions is given in Figure 4. A significant increase of the coating thickness was observed up to $2 \mathrm{~h}$ of treatment at both the used temperatures. The first significant increase was followed by a less pronounced increase in the coating primary layer thickness. 


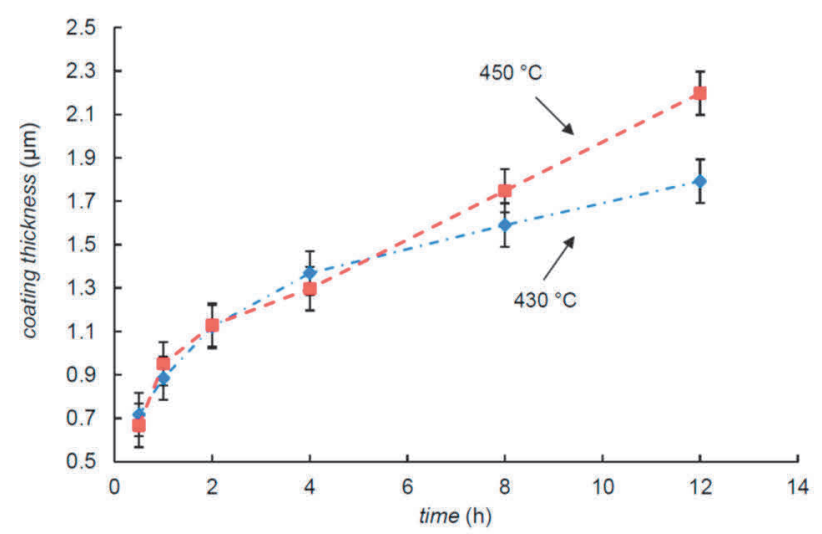

Figure 4 Coating thickness dependence on the coating time

\subsection{Electrochemical impedance spectroscopy}

Nyquist plots characterizing material electrochemical corrosion properties are shown in Figure 5.

A)
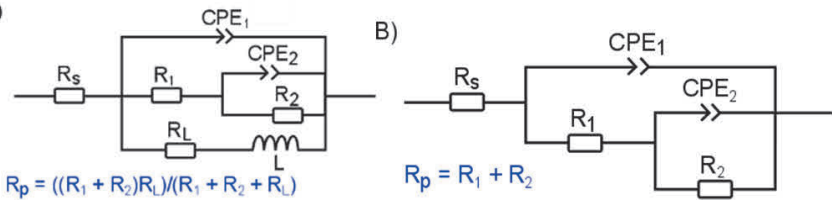

C)
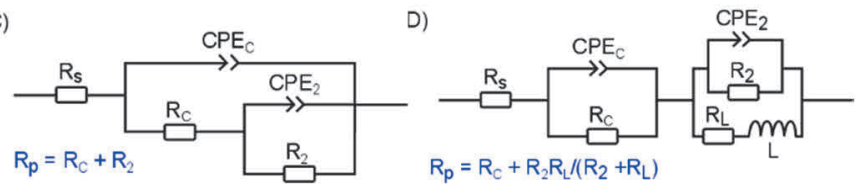

a) Equivalent circuits with $R_{p}$ expression

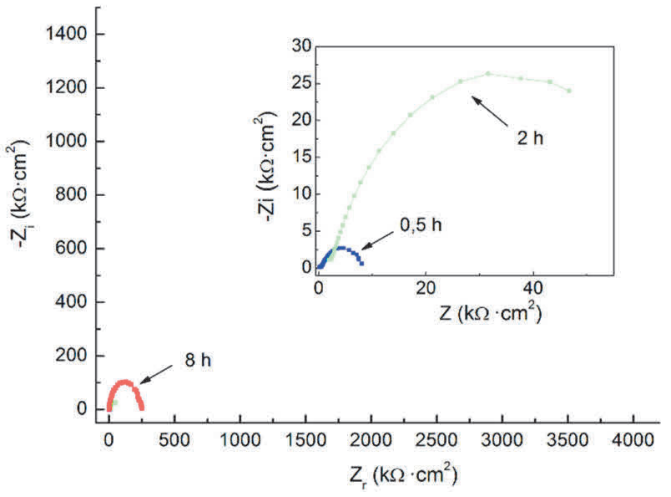

C) Coated at $430{ }^{\circ} \mathrm{C}$

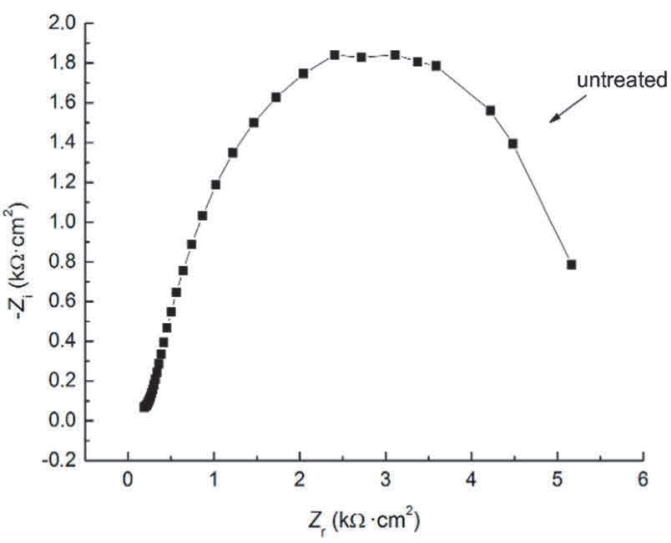

b) Untreated

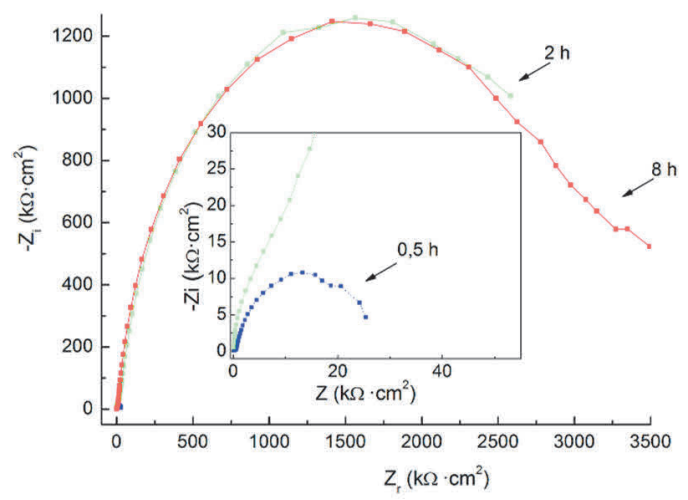

d) Coated at $450{ }^{\circ} \mathrm{C}$

Figure 5 EIS data for ZE10 after $168 \mathrm{~h}$ of immersion in SBF solution

The equivalent circuits (ECs) shown in Figures 5a-A and B, were used to fit the obtained EIS data for the untreated material. The ECs consist of a resistance of SBF, $R_{s}$, and $R_{1}, C P E_{1}$ are associated with the resistance of the created layer of corrosion products and constant phase element, respectively [10]. CPE substitute the imperfect capacitor, describing the imperfections of the layer of corrosion products created on material and imperfectly protecting the metal from the corrosion environment [11]. The elements $\mathrm{R}_{2}$ and $\mathrm{CPE}_{2}$ are charge transfer resistance and constant phase element related to the electric double layer at the interface 
of the material and SBF, respectively. The element $L$ is inductance and $R_{L}$ is the resistance of the inductor element and resistance of the material. The ECs Figures $9 a-C$ and $D$ were used for fitting EIS data obtained by measuring coated ZE10. The elements $R_{C}$ and $C P E_{C}$ stands for the resistance and the constant phase element of the prepared coating. Obtained EIS data were analysed with EC-lab software using the appropriate EC model. Figures 5b-d shows the Nyquist plots characterizing electrochemical corrosion behaviour of untreated and coated ZE10 after $168 \mathrm{~h}$ of immersion in SBF. The values of the polarization resistance, $\mathrm{R}_{\mathrm{p}}$, calculated according to the equations presented in Figure 5 a are given in Table 1.

Table 1 Values $\mathrm{Rp}_{\mathrm{p}}{ }^{*}$ obtained from EIS measurements performed in SBF

\begin{tabular}{|c|c|c|c|c|c|c|c|}
\hline \multirow{2}{*}{ Coating time (h) } & \multirow{2}{*}{$\begin{array}{l}\text { Untreated } \\
\text { ZE10 }\end{array}$} & \multicolumn{3}{|c|}{ Coating temperature $430{ }^{\circ} \mathrm{C}$} & \multicolumn{3}{|c|}{ Coating temperature $450{ }^{\circ} \mathrm{C}$} \\
\hline & & 0.5 & 2 & 8 & 0.5 & 2 & 8 \\
\hline Immersion time & \multicolumn{7}{|c|}{$R_{\mathrm{p}}\left(\mathrm{k} \Omega \cdot \mathrm{cm}^{2}\right)$} \\
\hline $5 \min$ & $3.9^{\mathrm{B}}$ & $19^{C}$ & $177^{\mathrm{D}}$ & $7144^{\mathrm{D}}$ & $90^{C}$ & $8,011^{\mathrm{D}}$ & $39,670^{\mathrm{D}}$ \\
\hline $1 \mathrm{~h}$ & $0.4^{\mathrm{A}}$ & $29^{C}$ & $922^{\mathrm{D}}$ & $20,250^{C}$ & $73^{C}$ & $11,940^{\mathrm{D}}$ & $46,300^{\mathrm{D}}$ \\
\hline $2 \mathrm{~h}$ & $0.8^{A}$ & $11^{c}$ & $3,163^{\mathrm{D}}$ & $5,095^{C}$ & $62^{C}$ & $2,414^{\mathrm{D}}$ & $50,110^{\mathrm{D}}$ \\
\hline $4 \mathrm{~h}$ & $3.5^{\mathrm{A}}$ & $16^{\mathrm{C}}$ & $2,459^{D}$ & $4,154^{\mathrm{C}}$ & $61^{c}$ & $4,799^{\mathrm{D}}$ & $58,570^{\mathrm{D}}$ \\
\hline $8 \mathrm{~h}$ & $6.4^{\mathrm{A}}$ & $21^{C}$ & $1,761^{\mathrm{D}}$ & $4,859^{C}$ & $95^{\mathrm{C}}$ & $7,334^{\mathrm{D}}$ & $61,230^{\mathrm{D}}$ \\
\hline $16 \mathrm{~h}$ & $6.8^{\mathrm{B}}$ & $18^{C}$ & $623^{D}$ & $3,748^{C}$ & $60^{c}$ & $3,045^{\mathrm{D}}$ & $41,860^{D}$ \\
\hline $24 \mathrm{~h}$ & $7.6^{\mathrm{B}}$ & $16^{\mathrm{C}}$ & $155^{\mathrm{D}}$ & $2,403^{C}$ & $74^{C}$ & $10,587^{\mathrm{D}}$ & $54,050^{\mathrm{D}}$ \\
\hline $48 \mathrm{~h}$ & $7.7^{\mathrm{B}}$ & $13^{\mathrm{C}}$ & $758^{\mathrm{D}}$ & $1,427^{\mathrm{C}}$ & $89^{C}$ & $12,555^{\mathrm{D}}$ & $21,012^{\mathrm{D}}$ \\
\hline $96 \mathrm{~h}$ & $6.1^{\mathrm{B}}$ & $11^{\mathrm{D}}$ & $90^{\mathrm{D}}$ & $418^{\mathrm{D}}$ & $24^{C}$ & $8,971^{\mathrm{D}}$ & $7,204^{\mathrm{D}}$ \\
\hline $168 \mathrm{~h}$ & $5.4^{\mathrm{B}}$ & $8.1^{\mathrm{D}}$ & $69^{\mathrm{D}}$ & $242^{D}$ & $27^{D}$ & $3,378^{D}$ & $4,059^{D}$ \\
\hline
\end{tabular}

* Indexes A, B, C and D correspond to the electrical equivalent circuit (Figure 5a) used for the determination of $R_{p}$ from measured data.

\section{DISCUSSION}

Unconventional fluoride conversion coating was successfully prepared on ZE10 magnesium alloy at both used treating temperatures $\left(430\right.$ and $450{ }^{\circ} \mathrm{C}$ ). The coatings were shown to be compact and homogenous however, the defects were mostly connected with the present intermetallic phases. The observations are in agreement with [8,9], analysing the coatings prepared on AZ61 magnesium alloys.

The results of EIS showed significantly positive influence of the coating on corrosion properties of ZE10, see Table 1. The change of the $R_{p}$ values of untreated ZE10 magnesium alloy were connected with the creation and damaging of the layer of corrosion products [12]. The coating prepared at both temperatures showed higher $R_{p}$ values when compared to the untreated alloy. The values of $R_{p}$ increased with increasing treatment time and temperature. The improvement of $R_{p}$ values of specimens with the coatings is in agreement with results obtained for conventionally prepared coatings (HF solutions) reported in [6-8]. However, as it was shown in [8], higher improvement of material electrochemical corrosion properties can be assumed for material with unconventional coating comparing with the conventional HF way of the coating preparation.

An increase of $R_{p}$ values during EIS (except the specimens prepared at $450{ }^{\circ} \mathrm{C}$ for $0.5 \mathrm{~h}$ ) can be related to penetration of SBF solution through the coating to ZE10. After that ZE10 reacted with SBF solution to form corrosion products and $\mathrm{H}_{2}$, damaging the coating. The created corrosion products can fill the defects of the coating and act as an effective barrier between corrosion environment and the base material. A followed decrease of $R_{p}$ values could be related to further penetration of SBF through the coating. 


\section{CONCLUSION}

The work was focused on the preparation and characterization of an unconventional fluoride conversion coating created on wrought ZE10 magnesium alloy. The results of the work can be summarized as follows:

- $\quad$ The coating was successfully prepared on ZE10 at temperatures of 430 and $450{ }^{\circ} \mathrm{C}$.

- Primary layer of the coating was composed of Mg-F system and particles of intermetallic phase $\mathrm{Mg}_{7} \mathrm{Zn}_{3}(\mathrm{RE})$ which contained $\mathrm{F}$ in its volume were incorporated in the coating layer.

- $\quad$ Coated specimens reached significantly higher values of $R_{p}$ when compared with the untreated ZE10.

\section{ACKNOWLEDGEMENTS}

This work was supported by the project "Materials Research Centre at FCH BUT - Sustainability and Development", REG L01211, with financial support from National Programme for Sustainability I (Ministry of Education, Youth and Sports), Czech Republic. This research has been financially supported by the Ministry of Education, Youth and Sports of the Czech Republic under the project $\mathrm{m}$ IPMinfra (CZ.02.1.01/0.0/0.0/16_013/0001823) and the equipment and the base of research infrastructure IPMinfra were used during the research activities. The research is supported by Science Grant Agency of the Slovak Republic through project No. 1/0045/17. Authors acknowledge the financial support for ERDF and Slovak state budget by the project ITMS26220220121.

\section{REFERENCES}

[1] ZHENG, Y.F, GU, X.N add WITTE, F. Biodegradable metals. Materials Science and Engineering: R: Reports. 2014, vol. 77, pp. 1-34.

[2] LI, L., GAO, J. and WANG, Y. Evaluation of cyto-toxicity and corrosion behavior of alkali-heat-treated magnesium in simulated body fluid. Surface and Coatings Technology. 2004, vol. 185, no. 1, pp. 92-98.

[3] CHIU, K.Y., WONG, M.H., CHENG, F.T. and MAN, H.C. Characterization and corrosion studies of fluoride conversion coating on degradable Mg implants. Surface and Coatings Technology. 2007, vol. 202, no. 3, pp. 590598.

[4] LI, J., HUANG, J., TIAN, Y. and LIU, C. Corrosion action and passivation mechanism of magnesium alloy in fluoride solution. Transactions of Nonferrous Metals Society of China. 2009, vol. 19, no. 1, pp. 50-54.

[5] DA CONCEICAO, T.F., SCHARNAGL, N., BLAWERT, C., DIETZEL, W. and KAINER, K.U. Surface modification of magnesium alloy AZ31 by hydrofluoric acid treatment and its effect on the corrosion behaviour. Thin Solid Films. 2010, vol. 518, no. 18, pp. 5209-5218.

[6] YAN, T., TAN, L., ZHANG, B. and YANG, K. Fluoride Conversion Coating on Biodegradable AZ31B Magnesium Alloy. Journal of Materials Science \& Technology. 2014, vol. 30, no. 7, pp. 666-674.

[7] YAN, T., TAN, L., XIONG, D., LIU, X., ZHANG, B. and YANG, K. Fluoride treatment and in vitro corrosion behavior of an AZ31B magnesium alloy. Materials Science and Engineering: C. 2010, vol. 30, no. 5, pp. 740-748.

[8] DRÁBIKOVÁ, J., FINTOVÁ, S., TKACZ, J., DOLEŽAL, P. and WASSERBAUER, J. Unconventional fluoride conversion coating preparation and characterization. Anti-Corrosion Methods and Materials. 2017, vol. 64, no. 6, pp. 613-619.

[9] FINTOVÁ, S., DRÁBIKOVÁ, J., PASTOREK, F., TKACZ, J., KUBĚNA, I., TRŠKO, L., HADZIMA, B., MINDA, J., DOLEŽAL, P.; WASSERBAUER, J. and PTÁČEK, P. Improvement of electrochemical corrosion characteristics of AZ61 magnesium alloy with unconventional fluoride conversion coatings. Surface and Coatings Technology. 2019, vol. 357, pp. 638-650.

[10] ASCENCIO, M., PEKGULERYUZ, M. and OMANOVIC, S. An investigation of the corrosion mechanisms of WE43 Mg alloy in a modified simulated body fluid solution: The influence of immersion time. Corrosion Science. 2014, vol. 87, pp. 489-503.

[11] LI, C.Q., XU, D.K., CHEN, X.-B., WANG, B.J., WU, R.Z., HAN, E.H. and BIRBILIS, N. Composition and microstructure dependent corrosion behaviour of Mg-Li alloys. Electrochimica Acta. 2018, vol. 260, pp. 55-64.

[12] SONG, G.L. and ATRENS, A. Corrosion mechanism of magnesium alloys. Advanced Engineering Materials. 1999, vol. 1, no. 1, pp. 11-33. 